\title{
The efficacy of multimodal intervention program on mental health states
}

\author{
Helena B. Florendo, Joseph V. del Rosario \\ College of Arts and Sciences, Isabela State University, Echague, Philippines
}

\begin{tabular}{|c|c|}
\hline Article Info & ABSTRACT \\
\hline $\begin{array}{l}\text { Article history: } \\
\text { Received Jan 15, } 2021 \\
\text { Revised Aug 22, } 2021 \\
\text { Accepted Sep 2, } 2021\end{array}$ & $\begin{array}{l}\text { Filipino youths are the hope of Philippine society. However, cigarette } \\
\text { smoking and binge drinking continually corrupt this aspiration. Mental health } \\
\text { states interplay with the growing setback of substance consumption. The } \\
\text { main objective of the study is to determine the efficacy of the multimodal } \\
\text { intervention program among the participants in this study. Specifically, it } \\
\text { answers the following objectives: i) Develop an intervention program to } \\
\text { address the high anxiety, mild depression, and normal self-esteem of the } \\
\text { participants and ii) Determine the significant difference between the control } \\
\text { group and the experimental group in the pre-test and post-test intervention } \\
\text { measures. A matched-group experimental design was carried out among the } \\
\text { participants who were randomly assigned to the control group and the } \\
\text { experimental group. There were forty participants who met the criteria set by } \\
\text { the researchers. When the multimodal intervention program was tested using } \\
\text { t-test to analyze the findings at .05 level, it yielded significant results. Based } \\
\text { on the findings of the study, the developed multimodal intervention program } \\
\text { appeared to be effective. A follow-up study may be conducted to further test } \\
\text { the efficacy. } \\
\text { This is an open access article under the CC BY-SA license. }\end{array}$ \\
\hline Corresponding Author: & BY SA \\
\hline $\begin{array}{l}\text { Helena B. Florendo } \\
\text { College of Arts and Sciences } \\
\text { Isabela State University } \\
\text { Echague, Isabela, Philippines } \\
\text { Email: helena.florendo28@ gmail.com }\end{array}$ & \\
\hline
\end{tabular}

\section{INTRODUCTION}

Students entering university for the first time may bear excitement and stress. They are thrilled because of the anticipated new events and encounters. On the other hand, this is also the phase that they are expected to experience the impact of university life like scholastic workload; homework, requirements, reports, research work, quizzes, and examinations. This might be aggravated by nostalgia since they left their home and their family. Freshman students are susceptible to the use of alcohol and nicotine since they are in their transition phase [1]-[3]. They are vulnerable to health hazards due to changes and challenges encountered in their new university/college life.

According to the World Health Organization, one of the most appropriate terms used in alcohol epidemiology to evaluate the burden arising through alcohol use is binge drinking [4]. Binge drinking is defined as $5+$ drinks per occasion [5]. It has been characterized as heavy drinking over such a relatively short time and is defined in females or males as 4 or 5 alcoholic beverages in a row [6]. The incidence of binge drinking in university students is indeed not easy to calculate since documented studies indicate various frequencies [6]. In all parts of the world, one of the main causes of death and illness is smoking [7]. The World Health Organization mentioned that approximately, 8 million annual mortality due to cigarette and smoking tobacco and the direct consumption of tobacco caused 7 million deaths. [7]. By the end of the 21st century, it is estimated that one billion people will die because of tobacco smokers [8]. In the book authored by Kasper, the several types of sickness like cancer, and other respiratory as well as cardiovascular diseases which can be preventable are caused by smoking [7]. There are various undesirable health consequences of 
both binge drinking and cigarette smoking and these are all hazardous to health. The mental health states that may cause the ingestion of substances are anxiety, depression, and self-esteem. In anxiety, uneasiness, nervousness, and fear could be felt. Depression is associated with loneliness, irritability, difficulty in coming up with decisions, and being pessimistic. Self-esteem is another mental health concern for students. Selfesteem is the positive or negative evaluation a person makes with regard to himself or herself. It also refers to beliefs, attitudes, and perceptions about oneself [9]. A positive self-esteem is an indicator of sound mental health and good social performance [10]. Positive self-esteem may allow people to make better decisions, such as adopting healthy habits [11], and it has a positive impact on mental health, and personality development [12] Negative self-esteem could lead to social problems like depression, anxiety, high-risk behaviors and substance use [10].

Among college freshman students, the problem emerges if mental health is challenged as a result of a transition that may lead to the consumption of alcohol and nicotine. When these become unmanageable, it may result in health risks and unhealthy behavior. Smoking or tobacco use was reported to be linked with anxiety symptoms [9], [10] and symptoms of depression [11]-[13]. Likewise, alcohol drinking is associated with depression, [14]-[16] anxiety, [17] and anxiety and depression [18]. Self-esteem is associated with smoking, [19] smoking and alcohol consumption [20], and alcohol use [21]. In the Philippines, the most commonly used substances by adolescents are alcohol and nicotine [22] and the consumption of these substances was high [23]. Likewise, the use of the illicit drug was also high [24]. Teenage years and early adulthood reflect crucial phases during which behaviours of substance use like alcohol, cigarettes and even drug use have been formed. These are critical times in which these habits are to be avoided. The increasing consumption of alcohol and smoking calls for the best solution to public health concerns [20]. Successful interventions are needed to facilitate the formation of attitudes among school children, to prevent adolescent risk behaviors, [21] and to build effective and safe coping strategies in times of crisis [25]. The regular use of alcoholic beverages and cigarette smoking among college students is alarming because these substances are addictive.

Worldwide, there are proliferations of various therapies in addressing the mental health problems however, in the Philippines, there is scarcity of research that deal on the mental health problems of alcohol drinkers and cigarette smokers. This research was conducted as an offshoot of the study conducted by Florendo and De Guzman [26]. This research was performed as a response to the need of creating an intervention program to deal with the mental health states high anxiety, mild depression, and average selfesteem of the college freshman binge drinkers and cigarette smokers. The main objective of the study is to determine the efficacy of the multimodal intervention program among the participants in this study. Specifically, it answers the following objectives: i) Develop an intervention program to address the high anxiety, mild depression, and normal self-esteem of the participants and ii) Determine the significant difference between the control group and the experimental group in the pre-test and post-test intervention measures. The researchers predicted that there was no significant difference in the mental states of the control group and the experimental group on the pre and post-intervention measures.

\section{RESEARCH METHOD}

In the preparation of the multimodal intervention program, the psycho-educational activities were reflected on how to decrease high anxiety, mild depression, and the enhancement of self-esteem. The intervention program was a combination of several activities to address the mental health states of the participants. It consists of relaxation exercises, classical music, relaxation exercises coupled with cognitive restructuring. Bioenergetic activities and movement activities or physical activities, dance moves, and video viewing, were also included in the program. Similarly, the multimodal intervention program emphasized the participants' strengths and weaknesses, as well as their roles and responsibilities.

A total of forty freshman college students at Isabela State University-Main Campus were purposely chosen as participants in this research. The participants were selected based on the following criteria: utilized 3-8 sticks of cigarettes and consumed 700-1,200ml of alcoholic beverages per day. The participants were identified through a pre-survey questionnaire. A matched-group experimental design was utilized by the researchers. The data gathered was analyzed through the Statistical Package for Social Sciences and paired sample test at 0.05 level of significance was used to analyze the data.

Beck anxiety inventory (BAI) was used to test anxiety while Beck Depression Inventory-II (BDI-II) was utilized to measure depression of the participants. Twenty-one anxiety and depression symptoms respectively were measured separately by BAI and BDI-II. Both inventories range from 0 to 3 and the diversity of scores could be attained from 0-63. High scores indicate a higher level of anxiety and depression, while lower scores mean lower anxiety and depression level. When the BAI was put to the test, the validity was $r=0.72$, the reliability was $r=0.83$, and the internal consistency was 0.92 [27]. Most BDI-II studies have reported a mean alpha coefficient of about 0.9 , ranging from 0.83 to 0.966 . The BDI-II is a valid and 
reliable instrument with .93 test-retest and .92 internal consistency [28]. This instrument is one of the most used questionnaires to measure the severity of depression, which can also be administered as a screening tool in non-clinical populations [28]. The Rosenberg Self-Esteem Scale (RSES) consists of 10 items to measure the comprehensive worth of a person. The answer on RSES ranges from 1 to 4 (strongly agree to strongly disagree) and the total range of score is 10 to 40 . On this scale, affirmative and negative statements measured self-esteem; both positive and negative self-worth. The higher the score, the higher one's selfesteem, while the lower one's self-esteem. RSES 'Cronbach's alpha coefficient was 0.86 [29]. When permission was obtained, the participants were identified. There is an ethical clearance from the participants. They were given an explanatory statement and informed consent which they signed before the conduct of the study. The explanatory statement and informed consent were elucidated for better understanding. The ethical principles of research were considered in the management of the participants.

\section{RESULTS AND DISCUSSION}

The discussions of the results of this study are presented in this section based on the objectives. The multimodal intervention program. The changes and adjustments encountered by freshman college students in their university life play a major role in the success of their academic life. It can not be denied that the stress they encounter influences their mental health states. They are frightened, threatened, discontented, and unhappy and at times become miserable. They are actually at risk. Thus, they are vulnerable to alcohol use and cigarette smoking. Studies conducted revealed that students relieve their anxiety [9], [10], [17], depression [11]-[16], and low self-esteem [19]-[21] through binge drinking and cigarette smoking. Hence, binge drinking and cigarette smoking could be realized through the underlying psychological explanation of ingesting these substances.

The Multimodal intervention program is a program developed by the researchers to address high anxiety, mild depression, and average self-esteem among the participants. The Intervention Program aims to help freshman college binge drinkers and cigarette smokers to 1) Determine techniques on how to manage their high anxiety and mild depression; 2) Enhance their self-esteem; and 3) Discover discerning attitude for growth, learning, and change in personal life.

The Multimodal Intervention Program consisted of various activities to address the mental health states of the participants. The intervention program started with a mood setting and trust building activity to establish rapport and ended with a prayer. To deal with high anxiety, relaxation activities like hypnotic induction, classical music, and hypnotic induction with cognitive restructuring were provided. The following bioenergetic activities were presented for the treatment of mild depression and self-esteem enhancement: self-awareness through muscle tension, movement activities or physical activities, video viewing while imitating dance moves, and expression of free dance movements while rock music was played.The identification of participants' strengths and weaknesses, as well as their roles and responsibilities, was also included.The intervention program consisted of specific objectives per activity, materials used were identified, procedures were indicated, and processing of the activity were done. The intervention activity was conducted twice a week for three months after classes of the participants in a psychological laboratory. Significant difference between the control group and experimental group in the pre-test and post-test intervention measure.

Table 1 shows the differences in the participants' mental health states of anxiety, depression, and self-esteem between the control and experimental groups at .05 level of significance. The statistical results showed that for mental health state anxiety, the pre-test and post test in the control group showed that there was no significant difference $(\mathrm{p}=0.086)$. However, in the experimental group when the multimodal intervention is used, there is a decrease in the mental health state anxiety when the pre-test and post test results are compared $(\mathrm{p}=0.000)$, which is significant. Results revealed that the mental health state depression in the control group the pre and post test disclosed $(\mathrm{p}=0.577)$ which is insignificant. In the experimental group when the multimodal intervention program was utilized, the mental health state depression was reduced in the post-test $\mathrm{p}=0.000$ ) a significant difference was discovered.

As displayed in Table 1, in the control group, the mental health state self-esteem scores in the pretest and in the post-test, $(\mathrm{p}=0.29)$, which is not significant, were noted. In the experimental group, in the pretest and in the post-test, an increase in self-esteem was recorded $(\mathrm{p}=0.000)$, which is significant when the multimodal intervention was used. The findings of the experiment conducted signify that the multimodal intervention program seems effective in reducing the level of symptoms of anxiety and depression and enhancing the self-esteem of the participants. In the control group, there is no significant difference in the performance of the respondents in the pre and post-intervention measures while in the experimental group, the hypothesis is rejected since there is a significant difference in the mental states of the respondents in the 
pre and post-intervention measures. Significant difference between the pre-test and post-test intervention measures in the control and experimental group.

Table 1. Significant difference between the control group and the experimental group in the pre-test and posttest intervention measures

\begin{tabular}{ccccccc}
\hline Mental health states & Pre-test & Post-test & Mean difference & Interpretation & t-value & $\mathrm{p}$-value \\
\hline Anxiety & & & & & & \\
$\quad$ Control group & 34.4 & 34.95 & -0.55 & Increased & $-1.814^{\mathrm{ns}}$ & 0.086 \\
Experimental group & 35.4 & 26.85 & 8.55 & Decreased & $15.968^{*}$ & 0.000 \\
$\quad$ Depression & & & & & \\
$\quad$ Control group & 13.15 & 13.3 & -0.15 & Decreased & $-0.567^{\mathrm{ns}}$ & 0.577 \\
Experimental group & 13.85 & 8.1 & 5.75 & Decreased & $17.78^{*}$ & 0.000 \\
$\quad$ Self-esteem & & & & & \\
$\quad$ Control group & 21.70 & 21.25 & 0.45 & Decreased & $1.088^{\mathrm{ns}}$ & 0.29 \\
Experimental group & 20.65 & 27.45 & -06.8 & Increased & $-13.88^{*}$ & 0.000 \\
\hline Legend: $\quad$ ns $=$ not significan & $*$ significant at .05 level of significance. &
\end{tabular}

The findings of this study are in agreement with the following various studies: Scientific investigations have proved that music is safe, useful and relevant [30]. Music can make you feel better; it can enhance, improve, or exacerbate your mood [31]-[33]. Music can also improve the quality of life, lessen anxiety [33]-[39], lessen negative affect [40] and can increase subjective well being or enhance psychological well being [35]-[37]. Respondents' under stressful conditions when exposed to classical music or music experienced less stress, less anxiety, become more calm [38], [39], [41]-[43], and relieve level of stress [44]. It was also revealed that depression was reduced through music [40], [45]-[47].

Induction is a mechanism that advises and facilitates the transfer of individuals from a regular state of consciousness and actions to a specific state of consciousness and action known as hypnosis or hypnotic trance [48]. The role of hypnotic induction was recognized to encourage an individual to progress to a therapeutic hypnotic state [48]. Efficient and effective induction must promote cognitive versatility, sensitivity, absorption, and dissociation, and must deliver these to patients in the most suitable manner (i.e., easiest) for them [48]. Hypnosis can facilitate many aspects that are immediately important to helping people who are depressed [49].

Hypnosis can be efficient and useful as an adjunct in managing depression [50]-[53], anxiety [51], [54], distress, and can increase self-esteem and optimism [54]. Similarly, combined hypnosis with cognitive behavior therapy is essential in managing depression and the treatment of various emotional disorders [55]. Hypnosis was also efficacious, especially when there are other interventions used in treating patients [56].

Several studies revealed that physical exercises and physical activity seemed effective in the reduction of symptoms of depression [57]-[62]. Physical exercises may also provide beneficial effects such as reduction of anxiety [58], [63]. The higher the level of physical activity, the lower the possibility of acquiring anticipated anxiety and even anxiety disorder [63]. There is is a significant relationship between physical activity and self-esteem among participants [64]. Positive results were found on the effect of physical activity and self esteem [65], [66] among students who participated in the research.

Among adolescents, it can be observed that rock music is appealing [66]. When a person hears and listens to fast music, he/she is carried away by the beat of the music. Dance movement appears to be cathartic [67]. Dance can be used in the treatment of depression and anxiety [68], [69]. When a person engaged in dance moves, the body and psychological endurance is affected to lessen the negative effects of their distress [70]. Video use can change and modify how an educator can teach and communicate with students. Video as a form of teaching is widely used not only in the Philippines but all over the world. Video is entertaining [69], video can be used as motivation, and a tool for new learning and teaching methods [70], [71]-[73]. Videos are useful and helpful in instruction [74].

\section{CONCLUSION}

The developed multimodal intervention program appeared useful and helpful in reducing high anxiety and mild depression symptoms and enhancing normal self-esteem among freshman college binge drinkers and cigarette smokers. The multimodal intervention program can be tested on a bigger population to validate the decrease in high anxiety, mild depression, and enhanced self-esteem. This intervention program may also be tried on students who are not binge drinkers and not cigarette smokers but have high anxiety and mild depression and normal self-esteem to further test its efficacy.

Int. J. Public Health Sci., Vol. 10, No. 4, December 2021 : 785 - 792 


\section{REFERENCES}

[1] J.G. Bachman, K.N. Wadsworth, P.M. O'Malley, L.D. Johnston, and J.E. Schulenberg, "Smoking, drinking, and drug use in young adulthood: The impacts of new freedoms and new responsibilities," Psychology Press, Jun 2013.

[2] I.J. Chung and J. Chun, "Co-occurring patterns of smoking and alcohol consumption among Korean adolescents", The American Journal on Addictions, vol. 19, no. 3, pp. 252-256, May 2010, doi: 10.1111/j.15210391.2010.00032.x.

[3] L. Dierker et al., "Tobacco Etiology Research Network. Tobacco, alcohol, and marijuana use among first-year US college students: A time series analysis," Substance Use \& Misuse, vol. 43, no. 5, pp. 680-699, Jan 2008, doi: 10.1080/10826080701202684.

[4] E. Kuntsche, S. Kuntsche, J. Thrul, and G. Gmel, "Binge drinking: Health impact, prevalence, correlates and interventions," Psychology \& Health, vol. 32, no. 8, pp. 976-1017, Aug 2017, doi: 10.1080/08870446.2017.1325889.

[5] M.E. Patrick, Y.M. Terry-McElrath, ST. Lanza, J. Jager, J.E. Schulenberg, and P.M. O'Malley, "Shifting age of peak binge drinking prevalence: Historical changes in normative trajectories among young adults aged 18 to $30 "$, Alcoholism: Clinical and Experimental Research, vol. 43, no. 2, pp. 278-298, Feb 2019, doi: 10.1111/acer.13933.

[6] M.-P. Tavolacci, E. Boerg, L. Richard, G. Meyrignac, P. Dechelotte, and J. Ladne "Prevalence of binge drinking and associated behaviours among 3286 college students in France," BMC Public Health, vol. 16, no. 1, pp. 1-9, Dec 2016, doi: 10.1186/s12889-016-2863-x.

[7] P. Sharareh, T. Leili, M. Abbas, P. Jalal and G. Ali, "Determining correlates of the average number of cigarette smoking among college students using count regression models," Scientific Reports, vol. 10, no. 1, pp. 1-10, Jun 2020, doi: 10.1038/s41598-020-65813-4.

[8] Jalilian, F., Joulaei, H., Mirzaei-Alavijeh, M, Samannezhad, B., Berimvandi, P., Karami Matin, B, Mahboubi, M.,"Cognitive factors related to cigarettes smoking among college students: An application of theory of planned behaviour," Social Science, vol. 11, no. 7, pp. 1189-1193, 2016.

[9] D. Szinay, I. Tombor, C. Garnett, N. Boyt, and R. West, "Associations between self-esteem and smoking and excessive alcohol consumption in the UK: A cross-sectional study using the BBC UK Lab database," Addictive Behaviors Reports, vol. 1, no. 10, Dec 2019, doi: 10.1016/j.abrep.2019.100229.

[10] M. Mann, C. M. H. Hosman, H. P. Schaalma, and N. K. de Vries, "Self-esteem in a broad-spectrum approach for mental health promotion," Health Education Research, vol. 19, no. 4, pp. 357-372, Aug 2004, doi: 10.1093/her/cyg041.

[11] J. Arsandaux, G. Michel, M. Tournier, C. Tzourio, and C. Galéra, "Is self-esteem associated with self-rated health among French college students? A longitudinal epidemiological study: The i-Share cohort," BMJ Open, vol. 9, no. 6, pp. 1-11, Jun 2019, doi: 10.1136/bmjopen-2018-024500.

[12] J. Shi, L. Wang, Y. Yao, N. Su, X. Zhao, and F. Chen, "Family impacts on self-esteem in Chinese college freshmen," Frontiers in Psychiatry, vol. 8, pp. 1-7, Dec 2017, doi: 10.3389/fpsyt.2017.00279.

[13] F. M. Slomp, T. S. Bara, G. L. Picharski, and M.L. Cordeiro, "Association of cigarette smoking with anxiety, depression, and, suicidal ideation among Brazilian adolescents," Neuropsychiatric Disease and Treatment, vol. 15, pp. 2799-2808, 2019, doi: 10.2147/NDT.S217069.

[14] M. Fluharty, A. E. Taylor, M. Grabski, and M. R. Munafò, "The association of cigarette smoking with depression and anxiety: A systematic review," Nicotine \& Tobacco Research, vol. 19, no. 1, pp. 3-13, May 2016, doi: 10.1093/ntr/ntw140.

[15] A. L. Wilkinson, C. T. Halpern, and A. H Herring, "Directions of the relationship between substance use and depressive symptoms from adolescence to young adulthood," Addictive Behaviors, vol. 1, no. 60, pp. 64-70, Sept 2016, doi: 10.1016/j.addbeh.2016.03.036.

[16] M. Milic et al., "Tobacco smoking and health-related quality of life among university students: Mediating effect of depression," Plos One, vol. 15, no. 1, pp. 1-18, Jan 2020, doi: 10.1371/journal.pone.0227042.

[17] K. S. Walters, S. M. Bulmer, P. F. Troiano, U. Obiaka, and R. Bonhomme, "Substance use, anxiety, and depressive symptoms among college students," Journal of Child \& Adolescent Substance Abuse, vol. 27, no. 2, pp. 103-111, Mar 2018, doi: 10.1080/1067828X.2017.1420507.

[18] S. R. Kenney, G. T DiGuiseppi, M. K Meisel, S. G. Balestrieri, N. P. Barnett, "Poor mental health, peer drinking norms, and alcohol risk in a social network of first-year college students," Addictive Behaviors, vol. 84, pp. 151159, Sep 2018, doi: 10.1016/j.addbeh.2018.04.012.

[19] S.F. Acuff et al., "Depressive symptoms as predictors of alcohol problem domains and reinforcement among heavy drinking college students," Psychology of Addictive Behaviors, vol. 32, no. 7, pp. 792-799, Nov. 2018, doi: 10.1037/adb0000397.

[20] A.J. Bravo, M.R. Pearson, and J.M. Henson, "Drinking to cope with depressive symptoms and ruminative Thinking: A multiple mediation model among college students," Substance Use \& Misuse, vol. 52, no. 1, pp. 52-62, Jan 2017, doi: 10.1080/10826084.2016.1214151.

[21] W. Gao, S. Ping, and X. Liu, "Gender differences in depression, anxiety, and stress among college students: A longitudinal study from China," Journal of Affective Disorders, no. 263, pp. 292-300, Feb 2020, doi: 10.1016/j.jad.2019.11.121.

[22] A. C. C. Decendario, "Substance use among adolescents in Maitum, Sarangani Province: Basis for intervention program," International Journal of Advanced Research and Publications, vol 3, no. 5, pp. 39-42, May 2019.

[23] S. Ah Hong and K. Peltzer, "Early adolescent patterns of alcohol and tobacco use in eight association of south-east asian nations (ASEAN) member states," Substance Use \& Misuse, vol. 54, no. 2, pp. 288-296, 2019, doi: 10.1080/10826084.2018.1517797. 
[24] S.Yi, K. Peltzer, S. Pengpid, and I. H. Susilowati, "Prevalence and associated factors of illicit drug use among university students in the association of southeast Asian nations (ASEAN)," Substance abuse treatment, prevention, and Policy 12, no. 1, pp. 1-7, 2017, doi: 10.1186/s13011-017-0096-3.

[25] R. Nourse, P. Adamshick, J. Stoltzfus, "College binge drinking and its association with depression and anxiety: A prospective observational study," East Asian Archives of Psychiatry, vol. 27, no. 1, pp. 18-25, Mar 2017.

[26] H. B. Florendo and R. de Guzman, "Mental health problems of freshman college binge drinkers and cigarette smokers," Asian Journal of Social Sciences \& Humanities, vol. 3, no. 4, pp. 257-266, Nov 2014.

[27] T. Faranak, C. Rahimi, and S. Sajjadi, "Psychometric properties of beck depression inventory-II for high school children in Shiraz City, Iran," International Journal of School Health, vol. 4, no. 3, pp.1-6, 2017, doi: 10.5812/intjsh.41069.

[28] A. Marin-Urquiza, J.P. Ferreira, and D. Van, "Athletic identity and self-esteem among active and retired paralympic Athletes," European Journal of Sport Science, vol. 18, no. 6, pp. 861-871, Jul 2018, doi: 10.1080/17461391.2018.1462854.

[29] J. Peng, J. Zhang, L. Zhao, P. Fang, and Y. Shao, "Coach-athlete attachment and the subjective well-being of athletes: A multiple-mediation model analysis," International Journal of Environmental Research and Public Health, vol. 17, no. 13, pp. 1-11, Jan 2020, doi: 10.3390/ijerph17134675.

[30] J. Stewart, S. Garrido, C. Hense, and K. McFerran, "Music use for mood regulation: Self-awareness and conscious listening choices in young people with tendencies to depression," Frontiers in Psychology, vol. 10, pp. 1-12, May 2019, doi: 10.3389/fpsyg.2019.01199.

[31] K. Azam, E. E. zarch, and S. A. Zakerian, "Investigate the effects of Iranian traditional music and western classical music on physical performance, the normal profile of mood states and rate of perceived exertion," International Journal of Health Studies, vol. 2, no. 4, pp. 14-20, Jan 2017, doi: 10.22100/ijhs.v2i4.173.

[32] N. Daykin et al., "What works for wellbeing? A systematic review of wellbeing outcomes for music and singing in Adults," Perspectives in Public Health, vol. 138, no. 1, pp. 39-46, Jan 2018, doi: 10.1177/1757913917740391.

[33] J.A. Agni, B. Sarwono, and S. Suyanta, "The effectiveness of classical music therapy and progressive muscle relaxation therapy on anxiety levels," Midwifery and Nursing Research, vol. 2, no. 1, pp. 9-14, Mar 2020.

[34] D.E. Osmanoglu and H. Yilmaz, "The effect of classical music on anxiety and well-being of university students," International Education Studies, vol. 12, no. 11, pp. 18-25, 2019, doi: 10.5539/ies.v12n11p18.

[35] A.M. Croom, "Music practice and participation for psychological well-being: A review of how music Influences positive emotion, engagement, relationships, meaning, and accomplishment," Musicae Scientiae, vol. 19, no. 1, pp. 44-64, Mar 2015, doi: 10.1177/1029864914561709.

[36] A. Creech, S. Hallam, M.Varvarigou, H. McQueen, and H. Gaunt, "Active music making: a route to enhanced subjective well-being among older people," Perspectives in Public Health, vol. 133, no. 1, pp. 36-43, Jan 2013, doi: $10.1177 / 1757913912466950$

[37] J. Laohawattanakun et al., "Influence of music training on academic examination-induced stress in Thai adolescents," Neuroscience letters, vol. 487, no. 3, pp. 310-312, Jan 2011, doi: 10.1016/j.neulet.2010.10.045.

[38] M. de Witte, A. da Silva Pinho, GJ. Stams, X. Moonen, A. Bos, and S. van Hooren, "Music therapy for stress reduction: A systematic review and meta-analysis," Health Psychology Review, pp. 1-26, Nov 2020, doi: 10.1080/17437199.2020.1846580.

[39] Padam, N. Sharma, O.S. Sastri, S. Mahajan, R. Sharma, and D. Sharma, "Effect of listening to vedic chants and Indian classical instrumental music on patients undergoing upper gastrointestinal endoscopy: A randomized control trial," Indian Journal of Psychiatry, vol. 59, no. 2, pp. 21428, Apr 2017, doi: 10.4103/psychiatry.IndianJPsychiatry_314_16.

[40] S. Aalbers, M. Spreen, K. Pattiselanno, P. Verboon, A. Vink, S. van Hooren, "Efficacy of emotion-regulating improvisational music therapy to reduce depressive symptoms in young adult students: A multiple-case study design," The Arts in Psychotherapy, vol. 71, p. 101720, 2020, doi: 10.1016/j.aip.2020.101720.

[41] G. Sunitha, S. Algoodkar, and P.S. Smitha, "Effect of Indian classical music therapy on depression anxiety and stress levels in patients with depression measured by DASS-21: A Pilot Study," International Journal of Physiology, vol. 6, no. 2, pp. 128-133, 2018, doi: 10.5958/2320-608X.2018.00067.7.

[42] E. Afshinpour and A. Naseri, "Music therapy effectiveness on depression of women referring to Shiraz specialist social emergency center," Indian Journal of Positive Psychology, vol. 9, no. 3, pp. 393-397, Sep 2018, doi: 10.15614/ijpp\%2F2018\%2Fv9i3\%2F181039.

[43] J. M., Groarke, A., Groarke, M. J. Hogan, L. Costello, and D. Lynch, "Does listening to music regulate negative affect in a stressful situation? Examining the effects of self-selected and researcher-selected music using both silent and active controls," Applied Psychology: Health and Well-Being, vol. 12, no. 2, pp. 288-311, Jul 2020.

[44] Y. Istadi, "Students who are listening to classical music during anatomic identification test Have Lower Stress Level," Sains Medika: Jurnal Kedokteran dan Kesehatan, vol. 9, no. 2, pp. 78-84, Dec 2018, doi: 10.30659/sainsmed.v9i2.3144.

[45] T.P. Bell and D.O. Akombo, "Long-term music-listening's effects on blood pressure, heart rate, anxiety, and depression,” Journal of Alternative Medicine Research, vol. 9, no. 1, pp. 57-64, 2017. 
[46] A. Elham, and A. Naseri, "Music therapy effectiveness on depression of women referring to Shiraz specialist social emergency center," Indian Journal of Positive Psychology vol. 9, no. 2, pp. 324-328, 2018.

[47] J. Meyerson, "Self-talk monitoring and utilization for enhancing hypnotic induction," American Journal of Clinical Hypnosis, vol. 60, no. 2, pp. 149-158, Sep 2017, doi: 10.1080/00029157.2017.1289465.

[48] M.D. Yapko, "Hypnosis in the treatment of depression: An overdue approach for encouraging skillful mood Management," International Journal of Clinical and Experimental Hypnosis, vol. 58, no. 2, pp. 137-146, Mar 2010, doi: 10.1080/00207140903523137.

[49] I. Holdevici, "A brief introduction to the history and clinical use of hypnosis," Romanian Journal of Cognitive Behavioral Therapy and Hypnosis, vol. 1, no. 1, pp. 1-5, Jan 2014.

[50] D.C. Hammond, "Hypnosis in the treatment of anxiety-and stress-related disorders," Expert Review of Neurotherapeutics, vol. 10, no. 2, pp. 263-273, Feb 2010, doi: 10.1586/ern.09.140.

[51] Kirsch, Irving, and Carol B. Low, "Suggestion in the treatment of depression," American Journal of Clinical Hypnosis 55, no. 3, pp. 221-229, Jan 2013.

[52] Untas, Aurélie, P. Chauveau, C.D.-Goudable, A.Kolko, F. Lakdja, and N. Cazenave, "The effects of hypnosis on anxiety, depression, fatigue, and sleepiness in people undergoing hemodialysis: a clinical report," International Journal of Clinical and Experimental Hypnosis 61, no. 4, pp. 475-483, 2013, doi: 10.1080/00207144.2013.810485.

[53] Milling, Leonard S., Keara E. Valentine, Hannah S. McCarley, and Lindsey M. LoStimolo, "A Meta-Analysis of Hypnotic Interventions for Depression Symptoms: High Hopes for Hypnosis?," American Journal of Clinical Hypnosis, vol. 61, no. 3, pp. 227-243, Dec 2018, doi: 10.1080/00029157.2018.1489777.

[54] I. Holdevici and B. Crăciun, "Hypnosis in the treatment of patients with anxiety disorders," Procedia-Social and Behavioral Sciences, no. 78, pp. 471-475, 2013, doi: 10.1016/j.sbspro.2013.04.333.

[55] K.E. Valentine, L.S. Milling, L.J. Clark, and C.L. Moriarty, "The efficacy of hypnosis as a treatment for anxiety: A meta-analysis," International Journal of Clinical and Experimental Hypnosis, vol. 67, no. 3, pp. 336-363, Jul 2019, doi: 10.1080/00207144.2019.1613863.

[56] A.P. Bailey, S.E. Hetrick, S. Rosenbaum, R. Purcell, and A.G. Parker, "Treating depression with physical activity in adolescents and young adults: A systematic review and meta-analysis of randomized controlled trials," Psychological Medicine, vol. 48, no. 7, pp. 1068-1083, May 2018, doi: 10.1017/S0033291717002653.

[57] S.L. Battalio, S.E. Huffman, and M.P. Jensen, "Longitudinal associations between physical activity, anxiety, and depression in adults with long-term physical disabilities," Health Psychology, vol. 39, no. 6, pp. 529-538, Jun 2020, doi: 10.1037/hea0000848.

[58] K.W. Choi et al., "Assessment of bidirectional relationships between physical activity and depression among adults: A 2-sample mendelian randomization study," JAMA Psychiatry, vol. 76, no. 4, pp. 399-408, Apr 2019, doi: 10.1001/jamapsychiatry.2018.4175.

[59] L.P. Dale, L. Vanderloo, S. Moore, and G. Faulkner, "Physical activity and depression, anxiety, and self-esteem in children and youth: An umbrella systematic review," Mental Health and Physical Activity, vol. 1, no. 16, pp. 66-79 Mar 2019, doi: 10.1016/j.mhpa.2018.12.001.

[60] T. McFadden, M.S. Fortier, and E. Guérin, "Investigating the effects of physical activity counselling on depressive symptoms and physical activity in female undergraduate students with depression: A multiple baseline singlesubject design," Mental Health and Physical Activity, vol. 12, no. 25, pp. 25-36, Mar 2017, doi: 10.1016/j.mhpa.2017.01.002.

[61] L. Mandolesi, "Effects of physical exercise on cognitive functioning and wellbeing: Biological and psychological benefits," Frontiers in Psychology, vol. 27, no. 9, pp. 1-11, Apr 2018, doi: 10.3389/fpsyg.2018.00509.

[62] M.C. Pascoe and A.G. Parker, "Physical activity and exercise as a universal depression prevention in young people: A narrative review," Early Intervention in Psychiatry, vol. 13, no. 4, pp. 733-739, Aug 2019, doi: 10.1111/eip.12737.

[63] F.B. Schuch et al., "Physical activity protects from incident anxiety: A meta-analysis of prospective cohort studies," Depression and Anxiety, vol. 36, no. 9, pp. 846-858, Sep 2019, doi: 10.1002/da.22915.

[64] N. Neeraj and P.S. Ahluwalia, "Physical activity, self-esteem and body composition among male college teachers", European Journal of Physical Education and Sport Science, vol. 6, no. 5, pp. 109-121, Jul 2020, doi: 10.46827/ejpe.v6i5.3199.

[65] S. Batsiou, S. Bournoudi, P. Antoniou, and S.P. Tokmakidis, "Self-perception self-esteem physical activity and sedentary behavior of primary greek-school students: A pilot study," International Journal of Instruction, vol. 13, no. 1, pp. 267-278, Jan 2020, doi: 10.29333/iji.2020.13118a.

[66] G. Russo, F. Nigro, G. Raiola, and A. Ceciliani, "Self-esteem in physically active middle school students," Journal of Physical Education and Sport, vol. 1, no. 19, pp. 1984-1988, Oct 2019, doi: 10.7752/jpes.2019.s5295.

[67] M. Punkanen, S. Saarikallio, and G. Luck, "Emotions in motion: Short-term group form dance/movement therapy in the treatment of depression: A pilot study," The Arts in Psychotherapy, vol. 41, no. 5, pp. 493-497, Nov 2014, doi: 10.1016/j.aip.2014.07.001. 
[68] M.B. Badave, K. Bathia, S. Kanase, and A. Jadhav, "Effect of dance therapy on stress and anxiety in working women," Indian Journal of Public Health Research \& Development, vol. 11, no. 1, pp. 157-161, Jan 2020, doi: 10.37506/ijphrd.v11i1.384.

[69] S.C. Koch, R.F. Riege, K. Tisborn, J. Biondo, L. Martin, and A. Beelmann, "Effects of dance movement therapy and dance on health-related psychological outcomes: A meta-analysis update," Frontiers in Psychology, vol. 20, no. 10, pp. 1-28, Aug 2019, doi: 10.3389/fpsyg.2019.01806.

[70] R. B. Roy and G. T. McMahon, "Video-based cases disrupt deep critical thinking in problem-based learning," Medical Education, vol. 46, no. 4, pp. 426-435, April 2012, doi: 10.1111/j.1365-2923.2011.04197.x.

[71] M. Debbag and M. Fidan, "Examination of text and video-formatted learning diaries in the teacher education," Australian Journal of Teacher Education, vol. 45, no. 3, pp. 1-17, 2020, doi: 10.14221/ajte.2020v45n3.1.

[72] W. Laaser and E.A. Toloza, "The changing role of the educational video in higher distance education," The International Review of Research in Open and Distributed Learning, vol. 18, no. 2, pp. 264-276 April 2017, doi: 10.19173/irrodl.v18i2.3067.

[73] R.D. Waters and P.M. Jones, "Using video to build an organization's identity and brand: A content analysis of nonprofit organizations' YouTube videos," Journal of Nonprofit \& Public Sector Marketing, vol. 23, no. 3, pp. 248268, July 2011, doi: 10.1080/10495142.2011.594779.

[74] J. M. D'Aquila, D. Wang, and A. Mattia, "Are instructor generated YouTube videos effective in accounting classes? A study of student performance, engagement, motivation, and perception," Journal of Accounting Education, vol. 47, pp. 63-74, 2019, doi: 10.1016/j.jaccedu.2019.02.002. 